\title{
Características de superdotação em um par de gêmeos monozigóticos
}

\author{
Carolina Sertã Passos' - Universidade Federal de Juiz de Fora, Juiz de Fora, Brasil \\ Altemir José Gonçalves Barbosa - Universidade Federal de Juiz de Fora, Juiz de Fora, Brasil
}

\begin{abstract}
Resumo
Com objetivo de comparar características de superdotação em um par de gêmeos monozigóticos, mais especificamente criatividade, motivação e capacidade superior, foram utilizados dados provenientes de um programa que identifica estudantes talentosos com o Modelo das Portas Giratórias. Os gêmeos responderam, também, ao Teste Torrance de Pensamento Criativo, à Escala de Avaliação da Motivação para Aprender de Alunos do Ensino Fundamental e à Bateria de Provas de Raciocínio. Eles possuem superdotação acadêmica e artística, sendo que um deles possui, também, altas habilidades para liderança e comunicação. Verificou-se que eles apresentaram elevada criatividade, principalmente verbal. O envolvimento com a tarefa, que neste estudo foi reduzido à motivação para aprender, não está presente em níveis superiores nos gêmeos. Mais semelhanças que diferenças entre os irmãos, talvez por eles compartilharem genes e ambientes, foram identificadas.

Palavras-chave: Altas habilidades, Superdotação, Gêmeos, Criatividade, Motivação, Desempenho.
\end{abstract}

\section{Characteristics of giftedness in a pair of monozygotic twins}

\begin{abstract}
Data from program that identifies talent through the Revolving Door Identification Model was used to compare characteristics of giftedness of a pair of monozygotic twins, specifically focusing on creativity, motivation and high ability. The twins also answered the Torrance Test of Creative Thinking, the Scale of Motivation to Learn in Elementary School Students and the Battery of Reasoning Tests. They have academic and artistic giftedness; one of them also has high leadership and communication skills. It was found that they showed great creativity, mainly verbal. Task commitment, which in this study was limited to motivation to learn, is not present at higher levels for the twins. More similarities than differences between the two brothers were identified, possibly because they share genes and environments.

Keywords: High ability, Giftedness, Twins, Creativity, Motivation, Performance.
\end{abstract}

Até recentemente, o pêndulo teórico no campo de estudo sobre o desenvolvimento humano pendia para a extremidade ambiental do contínuo. No entanto, na década de 1990, aproximadamente, ele oscilou de forma notável para as raízes biológicas do comportamento e do desenvolvimento (Bee, 2003). Esse movimento se manteve, em certa medida, até os dias atuais, graças aos avanços das neurociências. No caso dos indivíduos superdotados, o processo de análise dos determinantes não seguiu necessariamente esse curso. Inicialmente, o estudo das altas habilidades estava intimamente relacionado à inteligência, campo em que predominavam as concepções de base genética. Os primeiros estudos sobre inteligência eram voltados para a investigação sobre sua hereditariedade, tendo Galton como pioneiro ao publicar, em 1869, a Hereditariedade do gênio, no qual demonstrou que as habilidades do homem são herdadas, assim como os traços físicos (Simonetti, 2008). Binet, Simon e Terman concebiam a inteligência como algo marcado pela maturação das funções biológicas (Simonetti, 2008).

Para Kaufman e Sternberg (2008), a caracterização de uma pessoa como superdotada depende de um conjunto de critérios, não havendo, porém, um totalmente correto, pois cada um é baseado em

\footnotetext{
${ }^{1}$ Endereço para correspondência:

Avenida Rio Branco, nº: 1804/214 - CEP: 36015-510 - Juiz de Fora - MG.

Email: carolserta@hotmail.com
}

determinada(s) concepção(ões) de superdotação. Nesse sentido, existem diversas concepções que foram surgindo e evoluindo ao longo do tempo. Os autores supracitados dividem-nas em quatro ondas: $\left.1^{a}\right)$ modelos de domínio geral; $2^{\mathrm{a}}$ ) modelos de domínio específico; $3^{\mathrm{a}}$ ) modelos sistêmicos; e $4^{a}$ ) modelos desenvolvimentais. Verifica-se que as "ondas" representam distintas interpretações do papel da relação hereditariedade-ambiente na determinação de características de superdotação. Observa-se, também, que o dilema nature-nurture está presente até os dias atuais nos modelos teóricos de superdotação.

Uma forma de se analisar empiricamente, dentre as muitas existentes, a relação ambientehereditariedade-superdotação é o estudo de gêmeos monozigóticos. Segundo Renzulli e McGreevy (1986), até o final do século 19, os estudos com gêmeos eram praticamente inexistentes. Historicamente, a pesquisa com gêmeos tem se voltado mais para as questões biológicas e psicológicas, nas quais eles são usados no estudo da hereditariedade, do meio ambiente, das variáveis genéticas, bem como no estudo geral das diferenças individuais. Galton, no último quarto do século 19, foi o primeiro pesquisador que sugeriu o uso de gêmeos monozigóticos e dizigóticos como base para estudar a relativa influência de fatores genéticos e ambientais na inteligência (Renzulli \& McGreevy, 1986). 
Renzulli e McGreevy (1986) estudaram gêmeos e analisaram por que apenas um havia sido incluído no programa especial para superdotados. Dentre outros resultados, perceberam que a inclusão de apenas um gêmeo se deu mais com irmãos dizigóticos do que com monozigóticos, haja vista as semelhanças entre estes ser maior em razão da base genética. Identificaram, também, que a maioria dos gêmeos estudava em salas de aula separadas, o que fez, em muitos casos, com que professores diferentes realizassem a identificação e, por consequência, a avaliação pode ter sido diferenciada. Verificaram, ainda, que muitos pais relataram que essa separação gerava competição entre os filhos em casa. No entanto, para a maioria dos irmãos, a seleção de apenas um não causou problemas entre eles. Os autores perceberam que a ocorrência de problemas entre irmãos se dava sempre no par monozigótico, pois a concorrência, nesse caso, é maior por causa da composição genética dos indivíduos, que "competem" um com o outro em igualdade.

Outro estudo com gêmeos superdotados merecedor de destaque é o de Haworth e colaboradores (2009). Foram analisados 11 mil pares de gêmeos com superdotação intelectual vinculados a seis estudos de países europeus, da Austrália e dos EUA. Com base em um modelo estatístico, verificou-se que a influência genética foi alta $(0,50$, com um intervalo de confiança de $95 \%$ ) e a do ambiente compartilhado foi moderada $(0,28)$.

Vinkhuyzen, van der Sluis, Posthuma e Boomsma (2009) obtiveram resultados análogos aos de Haworth e colaboradores (2009) ao investigarem aptidões e talentos excepcionais em música, artes, escrita, linguagem, esporte, matemática, memória, conhecimento e xadrez em 1.685 pares de gêmeos. Tanto as aptidões quanto os talentos apresentaram pequena influência do ambiente compartilhado. Fatores genéticos explicaram melhor a variação nas aptidões e nos talentos nos diferentes domínios.

É preciso enfatizar que a forte influência da hereditariedade observada nas investigações não significa que as influências ambientais não são importantes, uma vez que, para atingir níveis excepcionais de destreza, a prática é indispensável, inclusive em pessoas com predisposições genéticas para desenvolver talento (Vinkhuyzen e colaboradores, 2009). Há que se destacar, também, que nos três estudos sobre gêmeos superdotados apresentados na presente revisão de literatura (Haworth e colaboradores, 2009; Renzulli \& McGreevy, 1986; Vinkhuyzen e colaboradores, 2009) foi ressaltada a necessidade de mais pesquisas sobre o problema.

Mesmo na literatura internacional, o estudo da superdotação constitui um campo de investigação que tem usado de forma relativamente tímida a pesquisa com gêmeos, especialmente monozigóticos. No contexto brasileiro, não há carência apenas de estudos sobre a relação entre altas habilidades e hereditariedade/ambiente, faltam investigações sobre superdotados em geral. Assim, o presente estudo pretende contribuir, ainda que minimamente, para suprir essa lacuna ao efetuar um estudo de caso de gêmeos monozigóticos participantes do Programa de Identificação e Desenvolvimento de Estudantes Talentosos (PIDET), em seu processo de identificação o Modelo das Portas Giratórias - MPG (Renzulli \& Reis, 1997).

A perspectiva dos Três Anéis (Renzulli, 1978, 1998) constitui o fundamento teórico dessa última proposta de identificação de superdotados. Nessa concepção, a superdotação é decorrente da confluência de três fatores: habilidade acima da média, envolvimento com a tarefa e criatividade.

A habilidade acima da média é definida como capacidade ou potencial para desempenho superior em alguma área do conhecimento. Podem ser consideradas tanto as habilidades gerais quanto as específicas. No primeiro caso, trata-se da capacidade de utilizar o pensamento abstrato e experiências passadas para a obtenção de respostas apropriadas e adaptáveis a novas situações ou problemas. O segundo caso diz respeito à capacidade de adquirir conhecimentos, técnicas e estratégias para executar uma atividade específica, como xadrez e dança. O envolvimento com a tarefa se refere à energia investida pelo indivíduo para realizar uma tarefa específica, ou seja, comportamentos que demonstram o interesse, motivação e empenho para a realização desta. A criatividade envolve vários aspectos, como, por exemplo, características do pensamento criativo, traços de personalidade e características de produto criativo, necessárias para a realização de projetos originais (Pereira, 2010; Renzulli, 1978, 1998; Virgolim, 2007).

A atual definição do Ministério da Educação (MEC) é fortemente influenciada pelo modelo dos Três Anéis de Renzulli, uma vez que ela considera alunos com altas habilidades/superdotação aqueles que demonstram potencial elevado em um ou mais dos seguintes domínios: intelectual, acadêmico, liderança, psicomotricidade e artes. Ela destaca, também, a elevada criatividade e o grande envolvimento na aprendizagem e realização de tarefas em áreas de interesse como características fundamentais de indivíduos que possuem essa necessidade educacional especial (Brasil, 2008).

O MPG é constituído por seis passos: 1) teste de inteligência; 2) nomeação por professores; 3) caminhos alternativos; 4) nomeações especiais; 5) notificação e orientação a pais; e 6) informação de ação (Renzulli, 1990; Virgolim, 
2005, 2007). Por meio desse modelo são definidos os alunos que irão compor o chamado "Pool de Talentos" (Renzulli \& Reis, 1997), que é o grupo que irá participar de um programa para superdotados.

No primeiro passo, são utilizados testes de inteligência e, a partir deles, são admitidos no grupo de talentos os alunos que obtiveram um resultado acima da média no(s) teste(s) ou em partes específicas do(s) teste(s) utilizado(s). No segundo passo, nomeação por professores, é indicado o uso de escalas de características que irão ajudar estes a avaliar os discentes em diversas áreas. $\mathrm{O}$ terceiro passo, caminhos alternativos, engloba as indicações feitas por pais, pares e a autonomeação, no caso dos mais velhos. Nesse passo podem, também, ser utilizados testes de criatividade, no intuito de incluir estudantes criativos, que normalmente não são percebidos como tais no ambiente escolar. O quarto passo, nomeações especiais, envolve a inclusão daqueles que tenham se destacado em anos anteriores, mesmo que este esteja apresentando um baixo rendimento, pois isso pode estar acontecendo por algum problema emocional, por exemplo. Ele é realizado pelo contato com professores de anos anteriores. O quinto passo, notificação e orientação aos pais, é feito ao final da formação do grupo de talentos. Nesse momento, os pais são informados sobre a indicação de seus filhos e convidados a participar de uma reunião com os responsáveis pela área de superdotação, em que o programa é apresentado e discutido. No último passo, nomeações através da informação da ação, podem ser incluídos ao longo do ano escolar, mediante a indicação de um professor, alunos que apresentem algum interesse incomum por alguma matéria ou conteúdo que esteja sendo estudado. (Renzulli, 1990; Virgolim, 2005, 2007).

O MPG é capaz de identificar os dois tipos de superdotação propostos por Renzulli: acadêmica e produtivo-criativa. A primeira é aquela mensurada pelos testes padronizados de capacidade cognitiva nos quais são medidas habilidades analíticas, as mais valorizadas pela educação escolar. As crianças e os adolescentes que se destacam nesse tipo geralmente tiram boas notas, têm facilidade para apreender e apresentam um nível de compreensão mais elevado que o de seus pares. Já o segundo tipo descreve aspectos da atividade e do envolvimento humanos, necessários para o desenvolvimento de ideias, produtos, expressões artísticas originais, ou seja, onde são percebidas habilidades criativas ou práticas. A pessoa com essa alta habilidade geralmente é mais questionadora, inventiva, imaginativa, sendo, em alguns casos, dispersiva quando o assunto não the interessa. Ela normalmente não gosta da rotina e costuma ter interesses diversificados. Segundo o autor, esta superdotação tende a ser contextual e específica de um domínio (Pereira, 2010; Renzulli, 1978, 1998, 2004; Virgolim, 2007).

\section{Objetivos}

O objetivo geral desta pesquisa foi comparar características de superdotação em um par de gêmeos monozigóticos. Especificamente, analisaram-se criatividade, capacidade superior e motivação.

\section{Método}

\section{Participantes}

Participaram do estudo dois alunos com 15 anos, cursando o nono ano do ensino fundamental de um colégio de aplicação de uma universidade pública e integrantes, há um ano, do PIDET. Foram considerados, também como participantes, seus pais e uma professora $(\mathrm{N}=1)$, bem como os pares $(\mathrm{N}=65)$, que forneceram informações sociométricas sobre os gêmeos. Dessa forma, participaram diretamente do estudo 67 estudantes, dois pais e uma professora.

A escolha dos casos foi feita de forma não probabilística. Consideraram-se, entre outros aspectos, $\mathrm{o}$ fato de ambos serem os únicos gêmeos monozigóticos participantes do PIDET e, provavelmente, os únicos da cidade identificados com características de altas habilidades/superdotação, o que contribuiu para a acessibilidade e a possibilidade de um contato efetivo com os indivíduos.

\section{Instrumentos}

Foram usadas informações provenientes do banco de dados do PIDET (Barbosa, 2008), sendo estas obtidas por meio dos instrumentos que fazem parte do MPG (Renzulli \& Reis, 1997). Destaca-se que esse programa adota o percentil local 92, sugerido por Renzulli (1990), como ponto de corte para todas as medidas e usa, dentre outros, os seguintes instrumentos:

1) Teste de inteligência - foi utilizado o teste Matrizes Progressivas de Raven - Escala Geral (Raven, 2003), que é constituído por 60 problemas com natureza nãoverbal, divididos em cinco séries (A, B, C, D e E) de 12 itens cada.

2) SRBCSS-R (Scales for Rating the Behavioral Characteristics of Superior Students - Revised edition) (Renzulli e colaboradores, 2004) - constituem um conjunto de formulários para nomeação por professores que avaliam 14 características: 1) aprendizagem; 2) motivação; 3) criatividade; 4) liderança; 5) comunicação: expressividade; 6) comunicação: precisão; 7) planejamento; 8) artes; 9) música; 10) drama; 11) ciências; 12) tecnologia; 13) matemática; e 
14) leitura. São disponibilizados quatro pontos de resposta: 1) raramente ou nunca; 2) ocasionalmente; 3) constantemente; e 4) quase sempre ou sempre (Barbosa e colaboradores, 2008).

3) Checklist de Características Associadas à Superdotação (CCAS) - trata-se de uma versão em língua portuguesa da Stand Up for your Gifted Child (Smutny, 2001), traduzida e adaptada por Barbosa e colaboradores (2008). Ela possui 42 afirmações sobre características de pessoas superdotadas, dez correspondendo ao domínio capacidade intelectual, vinte e quatro, ao domínio da criatividade, e oito, ao domínio emocional, e foi usada para a nomeação por pais.

4) Quest Student Nomination Questionnaire (QSNQ) (Renzulli \& Reis, 1997) - a tradução e adaptação para a língua portuguesa foi realizada por Barbosa, Miranda, Silva, Freitas e Almeida (2008) e constitui-se em um formulário onde um aluno indica o nome de um colega de sala que se destaca nas seguintes áreas: matemática, português, história, geografia, ciências, desenho, teatro, música, esportes, criatividade e liderança.

5) Quest Self Nomination Form (QSNF) (Renzulli \& Reis, 1997) - esse formulário de autonomeação também foi traduzido e adaptado para a língua portuguesa por Barbosa e colaboradores (2008). Trata-se de um instrumento no qual o aluno deve indicar em quais áreas julga possuir uma habilidade especial, justificando sua indicação com exemplos de realizações diferenciadas (Pereira, 2010).

Além dos dados constantes no banco de dados do PIDET, foram coletadas informações adicionais com os seguintes instrumentos:

1) Teste Torrance de Pensamento Criativo - TTCT (Torrance, 1966, 1990). O objetivo dele é a avaliação de aspectos relacionados ao processo criativo e à personalidade por meio da produção criativa expressa de forma verbal e figurativa. Foi adaptado e validado para a população brasileira por Wechsler (2002), contendo normas para estudantes do ensino médio e superior. Como os participantes deste estudo são do ensino fundamental, foi necessário realizar uma adaptação para esta faixa etária. Para tanto, foram empregados os procedimentos utilizados por Gonçalves (2010). Com isso, foram utilizados quatro subtestes do TTCT (forma A), dos quais dois são verbais e dois figurativos. Os subtestes verbais são: aperfeiçoamento do produto e usos diferentes. Já os dois subtestes figurativos são: completando figuras e linhas. Foram avaliadas por meio desses subtestes três características do pensamento criativo: (a) fluência, (b) flexibilidade, e (c) originalidade. O resultado referente à criatividade verbal é computado a partir da soma dos pontos obtidos nessas três características nos subtestes verbais, sendo distribuído, para fluência, um ponto para cada resposta. No caso da flexibilidade, computase um ponto para cada categoria diferente (p. ex. brinquedos, utensílios domésticos, animais) que aparecer nas respostas. A originalidade é pontuada com zero, um ou dois, de acordo com critérios previstos antecipadamente. O mesmo procedimento é realizado para a obtenção dos resultados relativos à criatividade figurativa. Destaca-se que não se calcula um total de criatividade verbal ou figurativa, sendo aferidos totais de fluência, flexibilidade e originalidade para cada uma dessas duas manifestações do pensamento criativo.

2) Escala de Avaliação da Motivação para Aprender de Alunos do Ensino Fundamental - EMA, desenvolvida por Neves e Boruchovitch (2007). Essa é uma escala de estrutura bifatorial com três pontos de resposta (sempre $=1$; às vezes $=2$; e nunca $=3$ ) para 34 itens divididos em dois fatores. O fator 1 - motivação intrínseca - é composto pelos 17 itens ímpares que devem ser espelhados para que escores elevados denotem alta capacidade de se motivar com a própria aprendizagem. A motivação extrínseca - fator 2 - é mensurada pelos itens pares, que devem, também, ser espelhados para que pontuações altas indiquem elevada dependência de estímulos externos como motivadores. Para obter o total desta medida, é preciso espelhar os itens referentes à motivação intrínseca e somá-los aos de motivação extrínseca não espelhados, pois, dessa forma, um escore total superior corresponde a um indicador de motivação intrínseca.

3) Bateria de Provas de Raciocínio (BPR-5) desenvolvido por Almeida e Primi (1998), este instrumento oferece estimativas do funcionamento cognitivo geral e das habilidades do indivíduo em cinco raciocínios: abstrato, verbal, espacial, numérico e mecânico. Ela é organizada em duas formas (A e B), com cinco subtestes cada. A forma A aplica-se aos estudantes do sétimo ao nono ano do ensino fundamental e a forma $\mathrm{B}$, aos alunos do primeiro ao terceiro ano do ensino médio. Pela faixa etária dos sujeitos da presente pesquisa, foi utilizada a forma $\mathrm{A}$.

Da mesma forma que o PIDET, adotou-se, para o TTPC, EMA e BPR-5, o ponto de corte 92. Porém, como detalhado mais adiante, nem sempre foi possível obter um percentil local para essas medidas baseado no grupo de pares dos gêmeos aqui estudados, sendo adotados outros critérios.

\section{Procedimento}

Após os cuidados éticos necessários (CAAE 0166.0.180.000-09), foram extraídas as informações iniciais do MPG do banco de dados do PIDET. Em seguida, foram aplicados, na própria escola, o TTPC, a EMA e a BPR-5, seguindo as normas de aplicação 
estabelecidas pelos instrumentos (local que garantia a confidencialidade etc.), bem como estabelecendo um bom rapport.

\section{Resultados}

A apresentação dos resultados segue a sequência proposta pelo MPG (Renzulli \& Reis, 1997), porém, ressalta-se que foram suprimidas as etapas de nomeações especiais e nomeação por informação da ação, pois os gêmeos analisados não poderiam ser mencionados nesses passos já que eles foram identificados em fases anteriores.

É importante reiterar que os instrumentos BPR-5, TTPC e EMA não foram usados no processo inicial de identificação do PIDET, sendo aplicados especificamente para o estudo em questão. Dessa forma, para análise dos resultados não puderam ser obtidos percentis locais, baseados no desempenho dos pares. Para a primeira dessas medidas, considerou-se somente o percentil nacional (Almeida \& Primi, 1998). O Teste de Torrance foi analisado com base nos resultados de Gonçalves (2010), uma vez que a autora utilizou o mesmo instrumento em estudantes da escola frequentada pelos gêmeos, ainda que tenha investigado uma amostra distinta da que fez parte deste estudo. Para a EMA, adotaram-se os escores obtidos por Barbosa, Oliveira e Silva (2010).

$\mathrm{Na}$ etapa de nomeação por teste (Tabela 1), verificou-se que Gêmeo 1 (G1) atingiu percentis acima de 92 - ponto de corte sugerido por Renzulli (1990) para essa fase - nas Matrizes Progressivas de Raven e na BPR-5. O Gêmeo 2 (G2), por sua vez, atingiu esse escore somente na BPR-5.

Tabela 1. Desempenho na nomeação por testes de gêmeos monozigóticos

\begin{tabular}{lcc}
\hline \multirow{2}{*}{ Nomeação por testes } & \multicolumn{2}{c}{ Participantes } \\
\cline { 2 - 3 } Matrizes Progressivas de Raven & Gêmeo 1 & Gêmeo 2 \\
Norma local & Percentil $>92$ \\
Norma nacional & $\begin{array}{c}\text { Percentil }>92 \\
\text { (Inteligência } \\
\text { superior) }\end{array}$ & Percentil $<92$ (Inteligência superior à média) \\
\hline BPR-5 & Percentil $>92$ & \\
Raciocínio abstrato & Percentil $>92$ & Percentil $>92$ \\
Raciocínio verbal & Percentil $>92$ & Percentil $>92$ \\
Raciocínio mecânico & Percentil $>92$ & Percentil $<92$ \\
Raciocínio espacial & Percentil $<92$ & Percentil $>92$ \\
Raciocínio numérico & Percentil $>92$ & Percentil $<92$ \\
Escore geral & Percentil $>92$ \\
\hline
\end{tabular}

Ao considerar a fase seguinte - nomeação por professores (Tabela 2) -, notou-se que o G1 foi nomeado apenas nas características de aprendizagem, enquanto o G2 foi indicado tanto nas características de aprendizagem quanto nas características de criatividade, comunicação (precisão e expressividade) e liderança.
Ressalta-se que a inclusão no grupo de talentos por meio da nomeação por professores considerou os estudantes nomeados em uma ou mais das SRBSS-R com percentil local - obtido a partir da turma em que estavam matriculados - igual ou superior a 92 (Pereira, 2010). 
Tabela 2. Nomeação por professores de gêmeos monozigóticos

\begin{tabular}{lcc} 
& \multicolumn{2}{c}{ Participantes } \\
\hline Características de aprendizagemão por professores & Gêmeo 1 & Gêmeo 2 \\
\cline { 2 - 3 } Características de motivação & Nomeado & Nomeado \\
Características de criatividade & Não nomeado & Não nomeado \\
Características de comunicação - precisão & Não nomeado & Nomeado \\
Características de comunicação - expressividade & Não nomeado & Nomeado \\
Características de liderança & Não nomeado & Nomeado \\
Características de planejamento & Não nomeado & Nomeado \\
Características de leitura & Não nomeado & Não nomeado \\
& Não nomeado & Não nomeado \\
\hline
\end{tabular}

Com base nos caminhos alternativos (Tabela 3), mais especificamente no que se refere à nomeação por pais, verificou-se que ambos não foram nomeados em nenhum dos domínios avaliados. Já na nomeação por pares, tanto G1 quanto G2 foram indicados no domínio artístico. Com relação à autonomeação, o G1 julgou ter habilidades especiais nas seguintes áreas: intelectual geral, música, matemática, ciências, criatividade, leitura, linguagem e artes. O G2 indicou música, matemática, ciências, criatividade, linguagem e judô. No TTTPC, foi verificado que o G1 atingiu o percentil 92 na avaliação da criatividade verbal, em todas as características avaliadas. Já o G2 só não atingiu esse percentil na avaliação da característica flexibilidade, mas ficou próximo. Com relação à criatividade figurativa, ambos não atingiram o percentil na característica fluência, no entanto atingiram percentil superior a 92 na característica originalidade. $\mathrm{Na}$ característica flexibilidade, G1 atingiu esse percentil e G2 ficou próximo dele. Quanto à EMA, verificou-se que os irmãos obtiveram escores muito próximos um do outro nas três medidas de motivação do instrumento, nenhum deles tendo sido classificado no percentil 92 ou superior.

Tabela 3. Nomeação por caminhos alternativos de gêmeos monozigóticos

\begin{tabular}{|c|c|c|}
\hline \multirow{2}{*}{ Caminhos alternativos } & \multicolumn{2}{|c|}{ Participantes } \\
\hline & Gêmeo 1 & Gêmeo 2 \\
\hline \multicolumn{3}{|l|}{ Nomeação por pais } \\
\hline Capacidade intelectual & Não nomeado & Não nomeado \\
\hline Criatividade & Não nomeado & Não nomeado \\
\hline Emocional & Não nomeado & Não nomeado \\
\hline Nomeação por pares & Nomeado (Artes) & Nomeado (Artes) \\
\hline \multicolumn{3}{|l|}{ TTPC - Criatividade verbal } \\
\hline Fluência & 39 (percentil > 92) & $38($ percentil $>92)$ \\
\hline Flexibilidade & 22 (percentil > 92) & $14($ percentil $\cong 92)$ \\
\hline Originalidade & 45 (percentil > 92) & $42($ percentil $>92)$ \\
\hline \multicolumn{3}{|l|}{ TTPC - Criatividade figurativa } \\
\hline Fluência & 25 (percentil < 92) & $20($ percentil $<92)$ \\
\hline Flexibilidade & 21 (percentil 92) & $20($ percentil $\cong 92)$ \\
\hline Originalidade & 34 (percentil > 92) & 27 (percentil $>92)$ \\
\hline \multicolumn{3}{|l|}{ EMA } \\
\hline Motivação intrínseca & 29 (percentil < 92) & 33 (percentil <92) \\
\hline Motivação extrínseca & 31 (percentil < 92) & 30 (percentil < 92) \\
\hline Total & 66 (percentil < 92) & $71($ percentil $<92)$ \\
\hline
\end{tabular}

Desse modo, o MPG revelou que tanto G1 quanto $G 2$ possuem características de superdotação nos domínios acadêmico e artístico, e, na última área, ambos frequentam uma escola de música e tocam profissionalmente. Um deles - G2 - possui, ainda, altas habilidades para liderança e comunicação. Verificou-se, também, que os irmãos possuem elevada criatividade, principalmente verbal. Constatou-se que o envolvimento com a tarefa, que neste estudo foi reduzido à motivação para aprender, não está presente em níveis superiores neles. 


\section{Discussão e Considerações finais}

Os resultados obtidos evidenciaram que os gêmeos analisados possuem tanto superdotação acadêmica quanto artística. Reitera-se que a primeira está relacionada com as habilidades analíticas, as mais valorizadas pela educação escolar. Os indivíduos que se destacam nesse tipo, geralmente tiram boas notas, têm facilidade para apreender e apresentam um nível de compreensão mais elevado que o de seus pares (Pereira, 2010; Renzulli, 1978, 1998, 2004; Virgolim, 2007). Já a superdotação artística envolve alto desempenho em artes plásticas, musicais, dramáticas, entre outras, sendo perceptíveis, por exemplo, pela facilidade para expressar ideias visualmente e sensibilidade ao ritmo musical (Virgolim, 2007). Especificamente no caso dos irmãos em questão, a área de destaque é a musical.

Essa constatação só foi possível porque o PIDET não adota a forma tradicional de identificação de características de altas habilidades. Reitera-se que foi por meio da nomeação por pares que se identificou a habilidade musical dos irmãos. Esse procedimento é parte dos caminhos alternativos, que não asseguram ingresso automático no grupo de superdotados (Renzulli, 1990), mas permite a inclusão de estudantes que, por algum motivo, não foram indicados anteriormente (Pereira, 2010).

A identificação de superdotados tem tomado como principal meio o uso de testes de inteligência, especialmente para a superdotação acadêmica, que é mais facilmente mensurada pelos testes padronizados de capacidade. Neles, os estudantes devem apresentar competências que são as mais valorizadas no meio escolar (Renzulli, 2004).

No contexto brasileiro, o teste Raven tem sido amplamente utilizado para avaliação da inteligência (Barbosa \& colaboradores, 2008; Virgolim, 2005), sendo considerado, inclusive, o mais adequado na identificação de minorias (Pereira, 2010). No entanto, a literatura sobre identificação de superdotados tem destacado a necessidade de se utilizarem diversas fontes de informação, inclusive testes, para o enriquecimento do processo (Oliveira, 2007; Pereira, 2010). Por isso, utilizou-se, também, a BPR-5, que, diferente do primeiro, permite uma avaliação multifatorial, identificando, assim, um maior número de informações acerca do avaliado. Essa estratégia permitiu identificar as habilidades intelectuais do G2, que não foram identificadas pelo Raven, e compreender melhor a forma de raciocínio de G1, uma vez que não se restringe a um domínio geral.

Ainda que tenham sido muito criticados, os testes têm grande importância no processo de identificação por permitirem que estudantes com inteligência acima da média, mas que não se destacam no meio escolar, não passem despercebidos (Virgolim, 2005). O caso G1, de certa forma, corrobora a afirmação anterior, pois ele não se destaca tanto quanto o irmão no contexto escolar, sendo nomeado pela professora apenas nas características de aprendizagem. Assevera-se que, no MPG, a inclusão através dos testes é automática (Renzulli, 1990).

Para Virgolim (2005), a nomeação por professores tem grande importância para o processo de identificação, pois os professores encontram-se em uma posição que favorece a identificação dos estudantes que apresentam características geralmente não acessadas por testes, como, por exemplo, criatividade, comunicação e liderança. Em consonância com essa assertiva, verificou-se que o G2 foi beneficiado por essa etapa da identificação, porque ele não foi nomeado no teste utilizado pelo PIDET e foi nomeado, nessa etapa, nas características de aprendizagem, criatividade, comunicação e liderança. Ressalta-se que, assim como no caso dos testes, a nomeação por professores inclui automaticamente os estudantes nomeados (Renzulli, 1990).

$\mathrm{Na}$ nomeação por pais, verificou-se que eles não nomearam um conjunto de características dos filhos suficientes para serem considerados superdotados nos domínios da capacidade intelectual, criatividade e emocional. Oliveira (2007) salienta que apesar de os pais possuírem informações não acessadas por testes ou por meio da escola, esse tipo de nomeação ainda é pouco utilizado na literatura. Essa autora assevera que muitos pais têm receio de que seu filho seja diferente, devido a problemas que a rotulação pode trazer. Para ela, o desenvolvimento de escalas de avaliação mais objetivas para essa nomeação pode contribuir para uma melhor eficácia dessa estratégia. $\mathrm{Na}$ nomeação por pares e por pais, a inclusão não é automática, havendo a necessidade de um estudo de caso para determinar ou não a inclusão dos estudantes nomeados (Renzulli, 1990). Enfatiza-se, também, que a escala utilizada não possui evidências de validade, o que pode ter enviesado os resultados.

Há que se recordar que, para a perspectiva dos Três Anéis, a superdotação é decorrente da interação de três fatores: habilidade acima da média; envolvimento com a tarefa; e criatividade. Contudo, para a inclusão no grupo de talentos, os estudantes não precisam, necessariamente, apresentar os três fatores no momento da avaliação (Renzulli, 1978, 1998). Devese lembrar que, no presente estudo, ambos apresentaram habilidade acima da média e criatividade. Porém, nenhum deles possui elevada motivação 
intrínseca, mas, também, não são motivados principalmente por estímulos extrínsecos.

O envolvimento com a tarefa se refere à energia investida pelo indivíduo para realizar uma tarefa específica, ou seja, comportamentos que demonstram o interesse, motivação e empenho para a realização desta (Pereira, 2010; Renzulli, 1978, 1998; Virgolim, 2007). Assim, trata-se de um construto mais abrangente que o medido pela EMA, que avalia somente motivação para aprendizagens escolares.

Uma avaliação mais rigorosa desse anel resultaria na constatação de que nenhum dos dois apresentou envolvimento com a tarefa, nesse caso tarefa escolar, em níveis superiores, pois somente um deles foi classificado no percentil 92 para o total da EMA. O envolvimento com a tarefa está relacionado essencialmente à motivação intrínseca, já que a motivação extrínseca não é capaz de promover um profundo envolvimento com a tarefa, uma vez que é controlada externamente (Renzulli, 1990).

É importante salientar que o presente estudo não foi capaz de delimitar as influências ambientais e hereditárias para o desenvolvimento de características de superdotação, como fizeram Vinkhuyzen e colaboradores (2009) e Haworth e colaboradores (2009), mas sinaliza a presença e a importância de ambas, pois os gêmeos são muitos semelhantes quanto às altas habilidades que apresentam. Como hipótese para explicar esse resultado, destaca-se o fato de eles compartilharem genes e ambientes - família, escola, comunidade etc. -, com exceção da sala de aula. É preciso reforçar, ainda, que a forte influência da hereditariedade observada nas investigações citadas não exclui a importância das influências ambientais, uma vez que, para atingir níveis excepcionais, a prática é indispensável, inclusive em pessoas com predisposições genéticas para desenvolver talento (Vinkhuyzen e colaboradores, 2009). Com isso, observa-se que o dilema nature-nurture persiste até os dias atuais, pois ainda existem dificuldades na separação das influências ambientais e hereditárias em razão da interação existente entre elas.

O presente estudo possui limitações, principalmente no que diz respeito aos instrumentos utilizados, uma vez que uma parcela significativa deles não possui ou tem carência de evidências de validade para o contexto brasileiro (p. ex. SRBCSS-R) e às características da amostra. Acrescenta-se que, no caso da EMA, ela mede apenas uma dimensão reduzida do construto envolvimento com a tarefa. Quanto à amostra, talvez, de fato, ela seja até uma força da presente investigação, pois há poucas pesquisas sobre superdotação em geral no Brasil e há menos ainda quando se trata de superdotados com características incomuns, como, por exemplo, gêmeos monozigóticos.
Não obstante as limitações mencionadas, os resultados obtidos têm implicações para a atuação de psicólogos escolares e outros educadores, uma vez que denota a importância do desenvolvimento das habilidades dos estudantes, já que a prática é indispensável inclusive em pessoas com predisposições genéticas. Além disso, este estudo possui relevância científica por contribuir para o debate da superdotação, uma área com produção científica reduzida no Brasil.

\section{Referências}

Almeida, L. S. \& Primi, R. (1998). Baterias de Provas de Raciocínio - BPR-5. São Paulo: Casa do Psicólogo.

Barbosa, A. J. G. (2008). Programa de Identificação de Estudantes Talentosos. (Projeto de Pesquisa). Juiz de Fora-MG: Universidade Federal de Juiz de Fora.

Barbosa, A. J. G., Oliveira, J. C. \& Silva, A. C. N. (2010). Bullying e motivação para aprender. Manuscrito não publicado, Juiz de Fora.

Barbosa, A. J. G., Miranda, O. B., Silva, J. D., Freitas, M. F. R. L. \& Almeida. C. S. (2008). Nomeação parental de estudantes talentosos: criatividade, capacidade intelectual e características emocionais. Em III Congresso Brasileiro de Educação Especial, 2008, São Carlos-SP. Anais do Congresso Brasileiro de Educação Especial. São Carlos: UFSCAR.

Barbosa, A. J. G., Pereira, C. E. S., Gonçalves, F. C., Passos, C. S., Miranda, O. B., Jesus, T. L., Silva, J. D. \& Moreira, P. S. (2008). Identificação de sobredotação intelectual: uso de testes e nomeação parental. Em XIII Conferência Internacional de Avaliação Psicológica: Formas e Contextos, 2008, Braga. XIII Actas de Avaliação Psicológica: Formas e Contextos. Braga: Psiquilibrios.

Bee, H. (2003). A criança em desenvolvimento. $9^{\mathrm{a}}$ ed. Porto Alegre: Artmed.

Brasil (2008). Ministério da Educação. Política Nacional de Educação Especial na Perspectiva da Educação Inclusiva. Brasilia: Autor.

Gonçalves. F. C. (2010). Estudo comparativo entre alunos superdotados e não superdotados em relação à criatividade, inteligência e percepção de clima de sala de aula para criatividade. (Dissertação de Mestrado). Brasília: Universidade Federal de Brasília: Programa de PósGraduação em Processos de Desenvolvimento Humano e Saúde.

Haworth, C. M. A., Wright, M. J., Martin, N. W., Martin, N. G., Boomsma, D. I., Bartels, M., Posthuma, D., Davis, O. S. P., Brant, A. M., 
Corley, R. P., Hewitt, J. K., Iacono, W. G., McGue, M., Thompson, L. A., Hart, S. A., Petrill, S. A., Lubinski, D. \& Plomin, R. (2009). A twin study of the genetics of high cognitive ability selected from 11,000 twin pairs in six studies from four countries. Behavior Genetics, 39, 359-370.

Kaufman, S. B. \& Sternberg, R. J. (2008). Conceptions of giftedness. Em S. I. Pfeiffer (Ed.). Handbook of giftedness in cbildren (pp. 71-91). Tallahassee, FL: Springer.

Neves, E. R. C. \& Boruchovitch, E. (2007). Escala de Avaliação da Motivação para Aprender de Alunos do Ensino Fundamental (EMA). Psicologia: Reflexão e Crítica, 20(3), 406-413.

Oliveira, P. (2007). Alunos sobredotados: a aceleração escolar como resposta educativa. (Tese de Doutorado). Braga: Universidade do Minho. Acesso em 02 de maio, 2010, em http://repositorium.sdum.uminho.pt

Pereira, C. E. S. (2010). Identificação de estudantes talentosos: uma comparação entre as perspectivas de Renzulli $e$ Güenther. (Dissertação de Mestrado). Juiz de Fora: Universidade Federal de Juiz de Fora - Programa de Pós-Graduação em Psicologia.

Raven, J. C. (2003). Matrizes progressivas: escala geral, séries $A, B, C, D e$ E. Rio de Janeiro: CEPA.

Renzulli, J. S. (1978). What makes giftedness? Reexamining a definition. Phi Delta Kappan, 60(261), 180-184.

Renzulli, J. S. (1990). A practical system for identifying gifted and talented students. Early Childhood Development, 63, 9-18.

Renzulli, J. S. (1998). The three-ring conception of giftedness. Em S. M, Baum, S. M. Reis \& Maxfield, L. R (Eds.). Nurturing the gifts and talents of primary grade students. (pp. 50-72). Mansfield Center, CT: Creative Learning Press.

Renzulli, J. S. (2004). O que é esta coisa chamada superdotação, e como a desenvolvemos? Uma retrospectiva de vinte e cinco anos. Educação, 1(52), $75-131$

Renzulli, J. S. \& McGreevy, A. M. (1986). Twins included and not included in special programs for the gifted. Roeper Review, 9(2), 120-127.

Renzulli, J. S. \& Reis, S. M. (1997). The schoolwide enrichment model: a how-to guide for educational excellence. Mansfield Center, CT: Creative Learning Press.
Renzulli, J. S., Smith, L. H., White, A. J., Callahan, C. M., Hartman, R. K. \& Westberg, K. L. (2004). Scales for rating the behavioral characteristics of superior students. Manual. Mansfield Center, CT: Creative Learning Press.

Simonetti, D. C. (2008). Superdotação: estudo comparativo da avaliação dos processos cognitivos através de testes psicológicos e indicadores neurofisiológicos. (Tese de Doutorado). Braga, Portugal: Universidade do Minho.

Smutny, J. F. (2001). Stand up for your gifted child: how to make the most of kid's strengths at school and at home. Minneapolis: Free Spirit Publishing Inc.

Torrance, E. P. (1966). Torrance tests of creative thinking. Lexington: Personnel Press.

Torrance, E. P. (1990). Torrance tests of creative thinking. Figural forms A and B. Benseville: Scholastic Testing Service.

Virgolim, A. M. R. (2005). A identificação do aluno com altas habilidades/ superdotação: fatores emocionais e desempenho escolar. Em Secretaria de Educação Especial (Org.). Ensaios pedagógicos: construindo escolas inclusivas (pp. 19-32). Brasília, DF: MEC - SEESP.

Virgolim, A. M. R. (2007). Altas habilidade/superdotação: encorajando potenciais. Brasília: Ministério da Educação - Secretaria de Educação Especial.

Vinkhuyzen, A. A. E., van der Sluis, S., Posthuma, D. \& Boomsma, D. I. (2009). The heritability of aptitude and exceptional talent across different domains in adolescents and young adults. Behavior Genetics, 39, 380-392.

Wechsler, S. M. (2002). Avaliação da criatividade por figuras e palavras - Testes de Torrance, Versão Brasileira. Cmapinas: LAMP/PUC - Campinas. 
Sobre os autores:

Carolina Sertã Passos é psicóloga e mestranda em Psicologia pela Universidade Federal de Juiz de Fora.

Altemir José Gonçalves Barbosa é psicólogo, mestre em Psicologia Escolar e doutor em Psicologia pela Pontifícia Universidade Católica de Campinas. Atualmente é professor adjunto I do Departamento de Psicologia e do Programa de Pós-Graduação em Psicologia da Universidade Federal de Juiz de Fora. 